\title{
BMJ Open Association between depression and overweight in Chinese adolescents: a cross-sectional study
}

\author{
Zhongyi Zhao, Ning Ding, Shenzhi Song, Yang Liu, Deliang Wen ${ }^{\odot}$
}

To cite: Zhao Z, Ding N, Song S, et al. Association between depression and overweight in Chinese adolescents: a crosssectional study. BMJ Open 2019;9:e024177. doi:10.1136/ bmjopen-2018-024177

- Prepublication history for this paper is available online. To view these files, please visit the journal online (http://dx.doi. org/10.1136/bmjopen-2018024177).

Received 16 May 2018 Revised 23 December 2018 Accepted 8 January 2019
D) Check for updates

(C) Author(s) (or their employer(s)) 2019. Re-use permitted under CC BY-NC. No commercial re-use. See rights and permissions. Published by BMJ.

School of Public Health, China Medical University, Shenyang, China

Correspondence to Professor Deliang Wen; dlwen@cmu.edu.cn

\section{ABSTRACT}

Objective Based on a nationally representative adolescent sample, we examined the association of depression on the prevalence of overweight or obesity and whether this association was moderated by gender.

Methods There were 1081 adolescents from the China Family Panel Studies that participated in our study. Depression in adolescents was assessed using the Center for Epidemiologic Studies Depression Scale (CES-D). Ordered logistic regression model was used to quantify its association with overweight or obesity. Analyses were performed for the total group, and separately for males and females.

Results The prevalence of depression in Chinese adolescents was $23.22 \%$. Depression (CES-D $\geq 16$ ) was significantly associated with overweight or obesity (OR=1.47, 95\% Cl: 1.14 to $1.91, \mathrm{p}=0.004$ ) after adjustment for personal, household and regional confounders. Among four subdimensions of depression, depressed affect and lack of positive affect were significantly associated with increases in the odds of overweight or obesity. In females, only lack of positive affect was significantly associated with overweight or obesity, whereas the estimated associations of all other measures of depression on overweight or obesity were positive in males.

Conclusions These findings provide evidence that depression is associated with overweight or obesity among adolescents in China, especially among males.

\section{INTRODUCTION}

Overweight and obesity in adolescents have become major public health concerns worldwide since their prevalence has increased substantially over recent decades, ${ }^{1}{ }^{2}$ especially in the developing world. ${ }^{3}$ For example, in China, there has been a significant and continuous increase in prevalence of obesity in adolescents, with an approximate 9\% annual increase during 1985-2010. ${ }^{4}$ In another large developing country, India, the overall prevalence of overweight or obesity in children is as high as $23.9 \%$ according to the WHO classification. ${ }^{5}$ Considering that overweight or obese adolescents are more likely to remain overweight or obese after maturing ${ }^{6}$ and that obesity is associated with many poor health outcomes, including cardiovascular

\section{Strengths and limitations of this study}

Our study was based on a nationally representative sample of Chinese adolescents, with adjustment of a wide range of important confounders, which makes the results relatively robust.

- Our study is one of the few studies that tend to clarify the association between depression and overweight or obesity and the gender differences in these associations additionally.

- The cross-sectional design of our study limits the value in supporting causal effects and generalisability of the results.

- Information on height and weight was obtained from subjective report, which, to some extent, resulted in response bias.

disease and metabolic syndrome, ${ }^{78}$ studies identifying risk factors of adolescent obesity will contribute to developing effective and efficient intervention strategies.

In addition to physical inactivity and excessive food intake, ${ }^{9}$ many researchers have begun investigating the effects of psychological features such as depression on the development of obesity. ${ }^{10-18}$ Although symptoms of depression might lead to obesity theoretically because they are closely related to several key obesogenic risk factors-such as physical activity, daily screen time and dietary intake,${ }^{19}$-empirical studies have not reached a consensus. For example, whether in clinical or non-clinical adolescent samples, depressed adolescents are at increased risk for development and persistence of obesity in the USA, ${ }^{14}{ }^{20}$ but for Korean ${ }^{21}$ and Island Puerto Rican adolescents, ${ }^{22}$ overweight or obesity is not related to high levels of depressive symptoms. One possible reason is that depression is multifaceted, including somatic, ${ }^{23}$ cognitive and affective dimensions. ${ }^{24}$ Dimensions of depression might affect adolescent obesity in different ways, and their effects possibly differ across different populations. Another reason could be the mediation role of cultural factors. ${ }^{25}$ The arguments above have not been 
confirmed and therefore cannot easily be generalised to China as the existing studies were mostly conducted in western countries. ${ }^{11} 141617$ There have been several studies in China to confirm the role of overweight or obesity in the development of depressive symptoms among young adolescents. ${ }^{26}{ }^{27}$ However, the association of depression on the prevalence of overweight or obesity and whether this association is moderated by gender remains unclear. Therefore, more investigations using valid and reliable measures of depression based on representative data from Asian countries are needed.

The association between depression and obesity in adolescents is of particular interest in the present study. By using a nationally representative sample of Chinese adolescents and a standardised self-reported scale of depression, we aimed to examine whether (1) depression was associated with overweight or obesity; (2) dimensions of depression differed in their association with overweight or obesity; and (3) there were gender differences in these associations.

\section{METHODS}

\section{Data source}

The data used in this study were obtained from the China Family Panel Studies (CFPS), which was a general-purpose, nationally representative, longitudinal social survey conducted by the Institute of Social Science Survey at Peking University in collaboration with the Survey Research Center at the University of Michigan. ${ }^{28}$ Extensive information on economic characteristics and health status was collected. ${ }^{29}$ In the second wave in 2012 , the Center for Epidemiologic Studies Depression Scale (CES-D) was introduced into questionnaires for assessing depression among adolescents aged 10-12 years, which was the area of interest of the present study. All relevant variables were extracted from three CFPS databases: variables of age, gender, height, weight, ethnicity, duration of breast feeding, birth weight and region were from the child database; maternal height, weight, and education level were from the adult database; and household income level was from the family database. Then, we matched the three kinds of variables with a unique identification code for each family and 1081 10-12year-old adolescents with complete information on CES-D and overweight or obesity status formed our sample.

All research data are publicly available (http://www. isss.pku.edu.cn/cfps/index.htm).

\section{MEASURES}

\section{Overweight and obesity}

Based on caregiver-reported height and weight, body mass index (BMI, $\mathrm{kg} / \mathrm{m}^{2}$ ) was calculated. Then, according to the criteria of the Working Group on Obesity in China, adolescents were categorised as obese if BMI was greater than or equal to the 95th percentile for age and gender or as overweight if BMI was greater than or equal to the 85 th percentile but less than the 95 th percentile. ${ }^{30}$

\section{Depressive symptoms}

The Chinese version of the CES-D, which was previously validated $^{31}$ and is widely used in studies on Chinese adolescents, ${ }^{32}$ was used to determine if individuals had symptoms of depression. Participants were asked to indicate the frequency of each depressive symptom experienced in the past week. This self-report scale comprises 20 items, which are answered on a four-point Likert scale (0-3 points). Among them, four items (Items 4, 8, 12 and 16) were reversely scored, which means the higher raw score they obtain, the less indicative of depression. The total score ranges from 0 to 60 with higher scores indicating higher levels of depression ${ }^{33}$ and a score of 16 represents the optimal cut-off point for identifying major depressive disorder. ${ }^{34}$ Additionally, the findings of factor analysis implemented by the CFPS group, showed that the four subdimensions of depressive symptoms (depressed affect, lack of positive affect, somatic symptoms and interpersonal problems) can be identified. Therefore, we had three measures of psychological depression: subjects who meet the cut-off point for depression $(\mathrm{CES}-\mathrm{D} \geq 16$ ); total CES-D scores; and four subdimensions of CES-D.

\section{Statistical analysis}

Only adolescents aged 10-12 years with complete information on BMI and CES-D were included in the current study. Further exclusion of those with extreme BMI values $\left(>40 \mathrm{or}<10 \mathrm{~kg} / \mathrm{m}^{2}\right)$ formed the final sample of 1081 adolescents. The missing values on confounders were imputed by using the multiple imputation technique. ${ }^{35}$ The convergence and dispersion trends for quantitative variables were expressed as mean \pm SD deviation and qualitative variables were expressed as frequencies and percentages. The prevalence of depression was calculated and the sociodemographical variables were compared between adolescents with and without depressive symptoms. Continuous variables were compared using the independent-samples t-test. Categorical variables were compared using Pearson's $\chi^{2}$ test or Fisher's exact test, as appropriate. A comparison of the total CES-D scores and the four subdimensions scores between different weight status groups was performed using one-way analysis of variance.

We ran separate ordered logistic regression models for each measure of depression, where the cut-off for CES-D was used as a binary variable, and the total CES-D scores and the four subdimensions scores were regarded as continuous variables in the model input. In our ordered logistic regression model, the weight status as the dependent variable was grouped by normal BMI, overweight and obesity. We ran separate ordered logistic regression models for each measure of depression. We first ran the regression models without controlling for any confounders (model 1). Model 2 controlled for a series of personal characteristic covariates of adolescents: 
gender (reference group: females) and age (in years), ethnicity (reference group: Han ethnic), duration of breast feeding (reference group: no breast feeding) and birth weight (reference group: normal birth weight). In model 3, we further adjusted for three covariates at the household level: maternal BMI, maternal education level (reference group: no schooling) and household income per capita (in $10^{3}$ RMB Yuan). In model 4 , we additionally introduced the interaction term between two confounders indicating where the adolescents were from: rural areas (reference group: urban areas) and regions (reference group: west). Finally, to determine the gender difference in any association between depressive symptoms and weight status, we reran all models after additionally introducing the interaction term between primary predictor variables and gender. SEs were clustered at the region level. Non-significance of test statistics of the parallel regression assumption for each model suggested that ordered logistic models might be appropriate. Two-sided $\mathrm{p}<0.05$ was considered significant. All analyses were performed using Stata $13 .^{36}$

\section{PATIENT AND PUBLIC INVOLVEMENT}

Patients were not involved in the development of the study. The results were intended for publication in a peer-reviewed journal, but there is no plan to specifically disseminate the findings to study participants.

\section{RESULTS}

The descriptive statistics for the 1081 adolescents aged 10-12 years showed that nearly one-fourth $(23.22 \%)$ of adolescents were depressed (table 1). In this special group, the prevalence of overweight and obesity were $13.15 \%$ and $11.95 \%$, respectively, which were significantly higher than those in the non-depression group $(9.88 \%$ and $6.75 \%$ respectively; $\left.\chi^{2}(2)=10.20, p=0.006\right)$. The summary statistics also indicated that those from ethnic minority groups, rural areas and western China were more likely to be depressed (table 1). Although maternal educational level was significantly associated with depression symptoms, duration of breast feeding, birth weight, maternal BMI and household income per capita were irrelevant. Table 2 shows the distribution of the total CES-D scores and the four subdimensions scores between different weight status groups (normal weight, overweight and obesity). We found an increasing trend for the CES-D scores by increasing weight status, although only the depressed affect and the interpersonal difficulties had significant associations with weight status $\left(\mathrm{F}_{(2,1078)}=4.92\right.$, $\mathrm{p}=0.001 ; \mathrm{F}_{(2,1078)}=3.16, \mathrm{p}=0.040$, respectively).

The results of model 1 (table 3 ) showed that the presence of depressive symptoms (CES-D $\geq 16$ ) was significantly associated with overweight or obesity $(\mathrm{OR}=1.70$, 95\% CI: 1.57 to $1.85, \mathrm{p}<0.001)$. Even after controlling for personal, household and regional confounders, the OR of 1.47 (95\% CI: 1.14 to 1.91) was still significant at
Table 1 Descriptive characteristics of the study subjects with and without depression

\begin{tabular}{|c|c|c|c|}
\hline & $\begin{array}{l}\text { Depressed } \\
\text { (CES-D } \geq 16)\end{array}$ & $\begin{array}{l}\text { Non-depressed } \\
\text { (CES-D<16) }\end{array}$ & \\
\hline & n (\%) & n (\%) & $P$ value \\
\hline Weight status & & & 0.006 \\
\hline Normal weight & $188(74.90)$ & 692 (83.37) & \\
\hline Overweight & $33(13.15)$ & $82(9.88)$ & \\
\hline Obese & $30(11.95)$ & $56(6.75)$ & \\
\hline Male & $128(51.00)$ & 432 (52.05) & 0.770 \\
\hline Age (year) & & & 0.041 \\
\hline 10 & $83(33.07)$ & 257 (30.96) & \\
\hline 11 & $95(37.85)$ & $262(31.57)$ & \\
\hline 12 & $73(29.08)$ & 311 (37.47) & \\
\hline Ethnic minorities* & $51(20.32)$ & $65(7.86)$ & 0.000 \\
\hline $\begin{array}{l}\text { Duration of } \\
\text { breast feeding } \dagger\end{array}$ & & & 0.411 \\
\hline None & $14(5.58)$ & $54(6.15)$ & \\
\hline $0-6$ months & $34(13.55)$ & 100 (12.06) & \\
\hline $6-12$ months & $113(45.02)$ & $370(44.63)$ & \\
\hline $12-18$ months & 47 (18.73) & $192(23.16)$ & \\
\hline$>18$ months & $43(17.13)$ & 113 (13.63) & \\
\hline Birthweight & & & 0.249 \\
\hline Low $(\leq 2.5 \mathrm{~kg})$ & $8(4.79)$ & $56(8.10)$ & \\
\hline Normal $(2.5-4 \mathrm{~kg})$ & 154 (92.22) & $606(87.70)$ & \\
\hline High $(\geq 4 \mathrm{~kg})$ & 5 (2.99) & $29(4.20)$ & \\
\hline $\begin{array}{l}\text { Maternal educational } \\
\text { level§ }\end{array}$ & & & 0.000 \\
\hline No school & $99(45.83)$ & $186(25.10)$ & \\
\hline Primary school & 57 (26.39) & 197 (26.59) & \\
\hline Middle school & $57(17.59)$ & 223 (30.09) & \\
\hline $\begin{array}{l}\text { High school or } \\
\text { higher }\end{array}$ & $22(10.19)$ & 135 (18.22) & \\
\hline Rural areas & 185 (73.71) & $478(57.59)$ & 0.000 \\
\hline Region & & & 0.000 \\
\hline West & $128(51.00)$ & $236(28.43)$ & \\
\hline East & 69 (27.49) & $254(30.60)$ & \\
\hline Central & $43(17.13)$ & $223(26.87)$ & \\
\hline Northeast & $11(4.38)$ & $117(14.10)$ & \\
\hline Total & $251(23.22)$ & $830(76.78)$ & \\
\hline
\end{tabular}

*Sample size is $1078, \dagger$ sample size is 1080 , $\neq$ sample size is 858 , §sample size is 957.

BMI, body mass index; CES-D, Center for Epidemiologic Studies Depression Scales.

$\mathrm{p}<0.01$ (model 4). When depression was measured by the CES-D scores, after introducing the confounders at the household level, the association between depression and overweight or obesity became non-significant. Among the four subdimensions of depression, the estimated effect of depressed affect was the largest (model $1, \mathrm{OR}=1.07$, 
Table 2 Comparisons of the Center for Epidemiologic Studies Depression Scale (CES-D) scores between different weight status groups

\begin{tabular}{|c|c|c|c|c|}
\hline & $\begin{array}{l}\text { Normal weight } \\
(\mathrm{n}=880)\end{array}$ & $\begin{array}{l}\text { Overweight } \\
(n=115)\end{array}$ & $\begin{array}{l}\text { Obesity } \\
(n=86)\end{array}$ & $P$ value \\
\hline CES-D scores & $31.17 \pm 6.52$ & $32.00 \pm 6.50$ & $33.57 \pm 7.33$ & 0.309 \\
\hline Positive affect & $8.83 \pm 2.64$ & $9.32 \pm 2.80$ & $9.40 \pm 2.67$ & 0.701 \\
\hline Somatic symptoms & $10.05 \pm 2.75$ & $10.11 \pm 2.51$ & $10.63 \pm 2.82$ & 0.408 \\
\hline
\end{tabular}

$95 \%$ CI: 1.05 to $1.10, \mathrm{p}<0.001$; model $4, \mathrm{OR}=1.06,95 \%$ CI: 1.02 to $1.10, \mathrm{p}=0.003)$, followed by lack of positive affect (model 1, OR=1.08, 95\% CI: 1.05 to $1.10, \mathrm{p}<0.001$; model 4, $\mathrm{OR}=1.04,95 \%$ CI: 1.03 to $1.05, \mathrm{p}<0.001)$. However, somatic symptoms and interpersonal difficulties did not affect overweight or obesity significantly in adolescents.

There was a gender difference in the association between depression and weight status (table 4). Only male adolescents with depression, but not females, had a higher risk of overweight or obesity irrespective of whether depression was measured with a binary (CES-D $\geq 16$ ) or a continuous variable (CES-D scores), and irrespective of which confounders were controlled for. Specifically, compared with non-depressed male adolescents, the overweight or obesity versus normal weight (or obesity versus overweight or normal weight) for the depressed group had OR of 1.48 (95\% CI: 1.24 to $1.76, \mathrm{p}<0.001$ ). When depression was measured using CES-D scores, a 1-unit increase in score was correlated with a $2 \%$ increase in the OR of overweight or obesity $(\mathrm{OR}=1.02,95 \% \mathrm{CI}$ : 1.01 to $1.04, \mathrm{p}=0.004$ ), which corresponded to each $\mathrm{SD}$ increase in CES-D scores $(31.45 \pm 6.61)$, resulting in a $13.22 \%$ increase in the risk of overweight or obesity. Additionally, detailed analysis showed that the estimated effect of the depressed affect on obesity was the same for male and female adolescents in magnitude, but only significant for males $(\mathrm{OR}=1.06,95 \%$ CI: 1.01 to $1.11, \mathrm{p}=0.009)$. Similarly, somatic symptoms and interpersonal difficulties were only associated with male obesity $(\mathrm{OR}=1.04,95 \% \mathrm{CI}$ : 1.01 to $1.07, \mathrm{p}=0.013$ and $\mathrm{OR}=1.14,95 \% \mathrm{CI}: 1.02$ to 1.27 , $\mathrm{p}=0.020$, respectively), although marginally significant. The fully adjusted model (model 4) showed that the lack of positive affect only had a significant effect on obesity for female adolescents at $\mathrm{p}<0.01$.

\section{DISCUSSION}

Using a nationally representative dataset, we demonstrated that depression (CES-D $\geq 16$ ) was a significant risk factor of overweight or obesity among adolescents in China independent of a wide array of confounding variables. Dimensions of depressed affect and lack of positive affect, rather than somatic symptoms or interpersonal difficulties, were significantly associated with overweight or obesity. Moreover, the association was genderedwhether depressed, depressed affect, somatic symptoms and interpersonal difficulties were all significantly associated with obesity among male adolescents, but for female adolescents only lack of positive affect was significant.

In the present study, the increased odds of overweight or obesity with depression among Chinese adolescents was consistent with the cross-sectional results of an earlier study of American adolescents indicating that depression and obesity with onsets by early adolescence (by age 14) were concurrently associated. ${ }^{37}$ Another cross-sectional study of adults also suggested that depression was a strong

\begin{tabular}{|c|c|c|c|c|}
\hline Variable & $\begin{array}{l}\text { Model } 1 \\
\text { OR }(95 \% \mathrm{Cl})\end{array}$ & $\begin{array}{l}\text { Model } 2 \\
\text { OR }(95 \% \mathrm{Cl})\end{array}$ & $\begin{array}{l}\text { Model } 3 \\
\text { OR (95\% Cl) }\end{array}$ & $\begin{array}{l}\text { Model } 4 \\
\text { OR }(95 \% \text { Cl) }\end{array}$ \\
\hline Whether depressed & $1.70(1.57 \text { to } 1.85)^{\star \star \star}$ & $1.63(1.35 \text { to } 1.97)^{\star \star *}$ & $1.48(1.11 \text { to } 1.97)^{\star \star}$ & $1.47(1.14 \text { to } 1.91)^{\star *}$ \\
\hline CES-D scores & $1.04(1.02 \text { to } 1.05)^{\star \star \star}$ & $1.03(1.01 \text { to } 1.05)^{\star \star}$ & 1.02 (0.99 to 1.05$)$ & $1.02(1.00$ to 1.05$)$ \\
\hline Depressed affect & $1.07(1.05 \text { to } 1.10)^{\star \star \star}$ & $1.07(1.04 \text { to } 1.10)^{\star \star \star}$ & $1.06(1.01 \text { to } 1.10)^{\star}$ & $1.06(1.02 \text { to } 1.10)^{\star *}$ \\
\hline Lack of positive affect & $1.08(1.05 \text { to } 1.10)^{\star \star \star ~}$ & $1.06(1.04 \text { to } 1.07)^{\star \star \star}$ & $1.04(1.03 \text { to } 1.06)^{\star \star \star}$ & $1.04(1.03 \text { to } 1.05)^{\star \star \star}$ \\
\hline Somatic symptoms & 1.04 (0.99 to 1.10$)$ & 1.03 (0.96 to 1.10$)$ & $1.02(0.94$ to 1.11$)$ & 1.02 (0.95 to 1.10$)$ \\
\hline Interpersonal difficulties & $1.17(1.04 \text { to } 1.32)^{\star \star}$ & 1.14 (0.98 to 1.33$)$ & 1.11 (0.92 to 1.33$)$ & 1.11 (0.92 to 1.33$)$ \\
\hline
\end{tabular}

Model 1: no adjustments; model 2: adjusted for age, gender, ethnic minority, duration of breast feeding and birth weight; model 3: additionally adjusted for maternal body mass index, maternal education and household income per capita on the base of model 2; model 4: additionally adjusted for the interaction between regions and urban areas on the base of model 3.

CES-D, Center for Epidemiologic Studies Depression Scales.

${ }^{\star} \mathrm{P}<0.05 ;{ }^{* *} \mathrm{P}<0.01 ;{ }^{* \star *} \mathrm{P}<0.001$. 
Table 4 Gendered difference in the association of CES-D scores and weight status

\begin{tabular}{|c|c|c|c|c|c|}
\hline Variable & Gender & $\begin{array}{l}\text { Model } 1 \\
\text { OR (95\% CI) }\end{array}$ & $\begin{array}{l}\text { Model } 2 \\
\text { OR }(95 \% \mathrm{Cl})\end{array}$ & $\begin{array}{l}\text { Model } 3 \\
\text { OR }(95 \% \mathrm{CI})\end{array}$ & $\begin{array}{l}\text { Model } 4 \\
\text { OR }(95 \% \mathrm{Cl})\end{array}$ \\
\hline \multirow{2}{*}{$\begin{array}{l}\text { Whether } \\
\text { depressed }\end{array}$} & Male & $1.69(1.35 \text { to } 2.13)^{\star \star \star}$ & $1.64(1.36 \text { to } 1.97)^{\star \star *}$ & $1.49(1.25 \text { to } 1.76)^{\star \star \star}$ & $1.48(1.24 \text { to } 1.76)^{\star \star *}$ \\
\hline & Female & $1.81(1.21 \text { to } 2.70)^{\star \star}$ & 1.63 (0.95 to 2.81$)$ & $1.47(0.76$ to 2.85$)$ & 1.46 (0.76 to 2.80$)$ \\
\hline CES-D scores & Male & $1.04(1.03 \text { to } 1.06)^{\star \star \star}$ & $1.03(1.01 \text { to } 1.04)^{\star \star \star}$ & $1.02(1.00 \text { to } 1.04)^{*}$ & $1.02(1.01 \text { to } 1.04)^{\star \star}$ \\
\hline Depressed affect & Female & 1.03 (0 to $98,1.07$ ) & 1.07 (0.98 to 1.16$)$ & $1.06(0.95$ to 1.17$)$ & 1.06 (0.96 to 1.16$)$ \\
\hline \multirow{2}{*}{$\begin{array}{l}\text { Lack of positive } \\
\text { affect }\end{array}$} & Male & $1.10(1.08 \text { to } 1.13)^{\star \star \star}$ & $1.03(1.01 \text { to } 1.05)^{\star \star}$ & 1.02 (0.98 to 1.06$)$ & 1.02 (0.98 to 1.06$)$ \\
\hline & Female & 1.03 (0.98 to 1.09$)$ & $1.09(1.04 \text { to } 1.15)^{\star \star \star}$ & $1.08(1.03 \text { to } 1.13)^{\star \star \star}$ & $1.08(1.03 \text { to } 1.13)^{\star \star}$ \\
\hline \multirow{2}{*}{$\begin{array}{l}\text { Interpersonal } \\
\text { difficulties }\end{array}$} & Male & $1.27(1.10 \text { to } 1.46)^{\star \star}$ & $1.15(1.06 \text { to } 1.26)^{\star \star}$ & $1.13(1.02 \text { to } 1.25)^{\star}$ & $1.14(1.02 \text { to } 1.27)^{\star}$ \\
\hline & Female & 0.99 (0.89 to 1.11$)$ & 1.12 (0.83 to 1.51$)$ & 1.07 (0.75 to 1.51$)$ & 1.05 (0.74 to 1.49$)$ \\
\hline
\end{tabular}

\begin{abstract}
${ }^{\star \star \star} \mathrm{P}<0.001$; ${ }^{* \star} \mathrm{P}<0.01$; ${ }^{*} \mathrm{P}<0.05$; model 1: no adjustments; model 2: adjusted for age, gender, ethnic minority, duration of breast feeding and birth weight; model 3: additionally adjusted for maternal body mass index, maternal education and household income per capita on the base of model 2; model 4: additionally adjusted for the interaction between regions and urban areas on the base of model 3.
\end{abstract}

CES-D, Center for Epidemiologic Studies Depression Scales.

and significant predictor of BMI in the Supplemental Nutrition Assistance Program. ${ }^{13}$ However, some studies failed to document any significant association. ${ }^{16212225}$ The inconsistencies between depression and obesity might be due to differences in sociodemographical characteristics of samples, assessments of depression and measurements of height and weight. For example, only depressed affect and lack of positive affect were significantly associated with overweight or obesity in the present study. Therefore, the estimated results were prone to be significant if an instrument of depression emphasising these two dimensions was employed.

Consistent with our findings, a cross-sectional study in 4150 US adolescents indicated that depression was significantly associated with obesity among males rather than females. ${ }^{16}$ However, several studies demonstrated that the association between depression and obesity was only significant among female adolescents, which needs further scientific attention. For example, a meta-analysis indicated that female adolescents with depression were 2.57 times more likely to have obesity status or weight gain at follow-up measurements. ${ }^{12}$ Another community-based study found that, for females, a history of depression was associated with greater yearly gains in BMI z-score compared with without a history of depression, whereas this association was not observed in males. ${ }^{11}$ Again, the reason could be that the association between each dimension of depression and obesity was also affected by gender. When the instrument of depression focused more on dimensions of depressed affect, somatic symptoms or interpersonal difficulties, the results were likely to be significant among male adolescents. In contrast, the estimates were prone to be significant among females if the instrument mainly emphasised the dimension of lack of positive affect. In addition, considering that positive affect could occur even if elevated levels of negative affect are present,${ }^{38}$ future studies on the relationship between depression and obesity should comprehensively evaluate the obesity effect of all dimensions of depression.

Our findings were similar to those reported in studies conducted in some western countries. ${ }^{11} 13161737$ However, among Asian adolescents, an association between depression and overweight or obesity has not been consistently confirmed, and cultural factors were considered a possible reason. ${ }^{21}{ }^{25-27}$ However, the present study suggests little, if any, mediation effect of culture on the association between depression and obesity in contemporary China. After China embraced an economic reform and open door policy in 1978, the Chinese people began to be exposed to a multicultural environment. As a result, the cultural gap between China and western countries narrowed due to adapting behaviours and reshaping preferences. For example, new generations in China do not give as much preference to male sons as their ancestors did. Thus, it is not surprising that the findings of the present study are consistent with those from western countries.

We conducted a nationally representative investigation of depression and overweight or obesity among Chinese adolescents independent of a wide array of confounding variables. However, several major limitations need to be 
acknowledged. First, the cross-sectional nature of the dataset used in the present study did not allow addressing the issue of causality. Second, we focused on the effects of depression on the development of obesity. However, the possible reverse causality might bias our estimation because, as recent longitudinal studies have highlighted, of the bidirectional association between depression and obesity. ${ }^{39-41}$ The clarification of whether psychiatric disorders and psychological problems are a cause or a consequence of childhood obesity among Chinese adolescents requires future longitudinal studies, which could address the reverse causality problem. Third, the measurement of overweight or obesity was calculated based on caregiver-reported height and weight, which might be inaccurate. However, previous studies confirmed that errors in such measurements were limited and did not lead to misclassification with regard to overweight or obesity in adolescent samples. ${ }^{14}{ }^{42-44}$ Finally, due to the cross-sectional nature of our research data, we were unable to observe the short-term weight changes (including weight loss and gain) caused by depression, which was mediated by factors such as decreased appetite, sleep disorders and so on. Future studies with longitudinal design were needed to systematically observe the short-term and long-term associations between depressive symptoms and weight changes among Chinese adolescent. Nevertheless, we applied appropriate analytical procedures to collect data comprehensively from a large, nationally representative cohort study and demonstrated that depression, particularly dimensions of depressed affect and lack of positive affect, might be a risk factor of obesity among Chinese adolescents and these influences could be modified by gender.

\section{CONCLUSIONS}

If depression is indeed a risk factor for being overweight or obese, then interventions aimed at improving mental health in Chinese adolescents could have major public health implications if they help prevent adolescents becoming overweight or obese. Considering the increasing prevalence of obesity among adolescents worldwide, it is critical to recognise the physiological and psychological characteristics among overweight and obese adolescents and to design corresponding interventions to promote both their physical and mental wellbeing in the current obesogenic environment.

Acknowledgements Data were collected from China Family Panel Studies (CFPS), funded by 985 Program of Peking University and carried out by the Institute of Social Science Survey of Peking University. We would like to thank BioMed Proofreading ${ }^{\circledR}$ [www.biomedproofreading.com] for English language editing.

Contributors Study design: DW; ZZ. Analysis of data: ND, YL. Interpretation of data: ZZ, SS.

Funding This research project was funded by Shenyang Science and Technology Plan Projects (F14-231-1-57) and Liaoning Distinguished Professor (Liaoning Education (2013) No.204).

Competing interests None declared.

Patient consent Not required.
Ethics approval Ethical approval for the study was granted by the Biomedical Ethics Committee of Peking University (Ref. IRB00001052-14010).

Provenance and peer review Not commissioned; externally peer reviewed.

Data sharing statement All data were available from website (http://opendata. pku.edu.cn/dataverse/CFPS).

Open access This is an open access article distributed in accordance with the Creative Commons Attribution Non Commercial (CC BY-NC 4.0) license, which permits others to distribute, remix, adapt, build upon this work non-commercially, and license their derivative works on different terms, provided the original work is properly cited, appropriate credit is given, any changes made indicated, and the use is non-commercial. See: http://creativecommons.org/licenses/by-nc/4.0/.

\section{REFERENCES}

1. World Health Organization. Obesity: preventing and managing the global epidemic. Report of a WHO consultation. World Health Organ Tech Rep Ser 2000;894:18-30.

2. Lobstein T, Jackson-Leach R, Moodie ML, et al. Child and adolescent obesity: part of a bigger picture. Lancet 2015;385:2510-20.

3. Misra A, Bhardwaj S. Obesity and the metabolic syndrome in developing countries: focus on South Asians. Nestle Nutr Inst Workshop Ser 2014;78:133-40.

4. Sun $\mathrm{H}, \mathrm{Ma} \mathrm{Y}, \mathrm{Han} \mathrm{D}$, et al. Prevalence and trends in obesity among China's children and adolescents, 1985-2010. PLoS One 2014;9:e105469.

5. Khadilkar VV, Khadilkar AV, Cole TJ, Chiplonkar SA, et al. Overweight and obesity prevalence and body mass index trends in Indian children. Int J Pediatr Obes 2011;6(2-2):e216-24.

6. Freedman DS, Khan LK, Serdula MK, et al. Racial differences in the tracking of childhood BMI to adulthood. Obes Res 2005;13:928-35.

7. Doyon A, Schaefer F. The prodromal phase of obesity-related chronic kidney disease: early alterations in cardiovascular and renal function in obese children and adolescents. Nephrol Dial Transplant 2013;28:iv50-7.

8. McMorrow AM, Connaughton RM, Lithander FE, et al. Adipose tissue dysregulation and metabolic consequences in childhood and adolescent obesity: potential impact of dietary fat quality. Proc Nutr Soc 2015;74:67-82.

9. Hill JO, Peters JC. Environmental contributions to the obesity epidemic. Science 1998;280:1371-4.

10. Pine DS, Cohen P, Brook J, et al. Psychiatric symptoms in adolescence as predictors of obesity in early adulthood: a longitudinal study. Am J Public Health 1997;87:1303-10.

11. Anderson SE, Cohen P, Naumova EN, et al. Association of depression and anxiety disorders with weight change in a prospective community-based study of children followed up into adulthood. Arch Pediatr Adolesc Med 2006;160:285-91.

12. Blaine B. Does depression cause obesity?: a meta-analysis of longitudinal studies of depression and weight control. $J$ Health Psychol 2008;13:1190-7.

13. Flórez KR, Dubowitz T, Ghosh-Dastidar MB, et al. Associations between depressive symptomatology, diet, and body mass index among participants in the supplemental nutrition assistance program. $J$ Acad Nutr Diet 2015;115:1102-8.

14. Goodman E, Whitaker RC. A prospective study of the role of depression in the development and persistence of adolescent obesity. Pediatrics 2002;110:497-504.

15. Korczak DJ, Lipman E, Morrison K, et al. Are children and adolescents with psychiatric illness at risk for increased future body weight? A systematic review. Dev Med Child Neurol 2013;55:980-7.

16. Merikangas AK, Mendola P, Pastor PN, et al. The association between major depressive disorder and obesity in US adolescents: results from the 2001-2004 National Health and Nutrition Examination Survey. J Behav Med 2012;35:149-54.

17. Roberts RE, Duong HT. Obese youths are not more likely to become depressed, but depressed youths are more likely to become obese. Psychol Med 2013;43:2143-51.

18. Javadi M, Jourabchi Z, Shafikhani AA, et al. Prevalence of depression and anxiety and their association with body mass index among high school students in Qazvin, Iran, 2013-2014. Electron Physician 2017:9:4655-60.

19. Dennison M, Sisson SB, Morris A. Obesogenic behaviours and depressive symptoms in children: a narrative literature review. Obes Rev 2016;17:735-57.

20. Fox CK, Gross AC, Rudser KD, et al. Depression, anxiety, and severity of obesity in adolescents: is emotional eating the link? Clin Pediatr 2016;55:1120-5. 
21. Ys N, Min SS, Dissatisfaction B. Self-Esteem, and depression in obese Korean Children. Journal of Pediatrics 2008;152:502-6.

22. Koinis-Mitchell D, Rosario-Matos N, Ramírez RR, et al. Sleep, depressive/anxiety disorders, and obesity in Puerto Rican Youth. J Clin Psychol Med Settings 2017;24:59-73.

23. Lecrubier Y. Physical components of depression and psychomotor retardation. J Clin Psychiatry 2006;67(Suppl 6):23-6.

24. Wesley AL, Gatchel RJ, Polatin PB, et al. Differentiation between somatic and cognitive/affective components in commonly used measurements of depression in patients with chronic low-back pain. Let's not mix apples and oranges. Spine 1991;16(6 Suppl):S213-5.

25. Chung KH, Chiou HY, Chen YH. Psychological and physiological correlates of childhood obesity in Taiwan. Sci Rep 2015;5:17439.

26. Li YP, Ma GS, Schouten EG, et al. Report on childhood obesity in China (5) body weight, body dissatisfaction, and depression symptoms of Chinese children aged $9-10$ years. Biomed Environ Sci 2007;20:11-18.

27. Wang $\mathrm{H}, \mathrm{Fu}$ J, Lu Q, et al. Physical activity, body mass index and mental health in Chinese adolescents: a population based study. $J$ Sports Med Phys Fitness 2014;54:518-25.

28. Xie Y, Hu J. An introduction to the China family panel studies (CFPS). Chinese sociological review 2014;47:3-29.

29. Xie Y, Lu P. The Sampling Design of the China Family Panel Studies (CFPS). Chin J Sociol 2015;1:471-84.

30. Ji CY. Working Group on Obesity in China. Report on childhood obesity in China (1)--body mass index reference for screening overweight and obesity in Chinese school-age children. Biomed Environ Sci 2005;18:390-400.

31. Li HC, Chung OK, Ho KY. Center for epidemiologic studies depression scale for children: psychometric testing of the Chinese version. J Adv Nurs 2010;66:2582-91.

32. Guo L, Deng J, He Y, et al. Prevalence and correlates of sleep disturbance and depressive symptoms among Chinese adolescents: a cross-sectional survey study. BMJ Open 2014;4:e005517.
33. Radloff LS. The CES-D scale a self-report depression scale for research in the general population. Applied psychological measurement 1977;1:385-401.

34. Fendrich M, Weissman MM, Warner V. Screening for depressive disorder in children and adolescents: validating the center for epidemiologic studies depression scale for children. Am J Epidemiol 1990;131:538-51.

35. Rubin DB, Schenker N. Multiple imputation in health-care databases: an overview and some applications. Stat Med 1991;10:585-98

36. StataCorp. Stata Statistical Software: Release 13. College Station, TX: StataCorp LP, 2013.

37. Marmorstein NR, lacono WG, Legrand L. Obesity and depression in adolescence and beyond: reciprocal risks. Int $J$ Obes 2014;38:906-11.

38. Folkman S. Positive psychological states and coping with severe stress. Soc Sci Med 1997;45:1207-21.

39. Luppino FS, de Wit LM, Bouvy PF, et al. Overweight, obesity, and depression: a systematic review and meta-analysis of longitudinal studies. Arch Gen Psychiatry 2010;67:220-9.

40. Rankin J, Matthews L, Cobley S, et al. Psychological consequences of childhood obesity: psychiatric comorbidity and prevention. Adolesc Health Med Ther 2016;7:125-46.

41. Roberts RE, Deleger S, Strawbridge WJ, et al. Prospective association between obesity and depression: evidence from the Alameda County Study. Int J Obes Relat Metab Disord 2003;27:514-21.

42. Goodman E, Hinden BR, Khandelwal S. Accuracy of teen and parental reports of obesity and body mass index. Pediatrics 2000;106(1 Pt 1):52-8.

43. Stunkard AJ, Albaum JM. The accuracy of self-reported weights. Am J Clin Nutr 1981;34:1593-9.

44. Stunkard AJ, Faith MS, Allison KC. Depression and obesity. Biol Psychiatry 2003;54:330-7. 